\title{
Increased frequency of combined methylenetetrahydrofolate reductase C677T and A1298C mutated alleles in spontaneously aborted embryos
}

\author{
Henrik Zetterberg ${ }^{\star}{ }^{1}$, Björn Regland ${ }^{2}$, Mona Palmér ${ }^{1}$, Anne Ricksten ${ }^{1}$, Lars Palmqvist ${ }^{1}$, \\ Lars Rymo ${ }^{1}$, Demetrios A Arvanitis ${ }^{3}$, Demetrios A Spandidos ${ }^{3}$ and Kaj Blennow ${ }^{1,4}$ \\ ${ }^{1}$ Department of Clinical Chemistry and Transfusion Medicine, Sahlgrenska University Hospital, Göteborg \\ University, Sweden; ${ }^{2}$ Institute of Clinical Neuroscience, Psychiatry Section, Sahlgrenska University Hospital, \\ Göteborg University, Sweden; ${ }^{3}$ Department of Virology, Medical School, University of Crete, Heraklion, Crete, \\ Greece; ${ }^{4}$ Institute of Clinical Neuroscience, Department of Experimental Neuroscience, Sahlgrenska University \\ Hospital, Göteborg University, Sweden
}

The pathogenesis of spontaneous abortion is complex, presumably involving the interaction of several genetic and environmental factors. The methylenetetrahydrofolate reductase (MTHFR) gene C677T and A1298C polymorphisms are commonly associated with defects in folate dependent homocysteine metabolism and have been implicated as risk factors for recurrent embryo loss in early pregnancy. In the present study we have determined the prevalence of combined MTHFR C677T and A1298C polymorphisms in DNA samples from spontaneously aborted embryos (foetal death between sixth and twentieth week after conception) and adult controls using solid-phase minisequencing technique. There was a significant odds ratio of $14.2(95 \% \mathrm{Cl} 1.78-113)$ in spontaneously aborted embryos comparing the prevalence of one or more $677 \mathrm{~T}$ and $1298 \mathrm{C}$ alleles vs the wild type combined genotype $(677 \mathrm{CC} / 1298 \mathrm{AA})$, indicating that the MTHFR polymorphisms may have a major impact on foetal survival. Combined $677 \mathrm{CT} / 1298 \mathrm{CC}, 677 \mathrm{TT} / 1298 \mathrm{AC}$ or $677 \mathrm{TT} / 1298 \mathrm{CC}$ genotypes, which contain three or four mutant alleles, were not detected in any of the groups, suggesting complete linkage disequilibrium between the two polymorphisms. The present finding of high prevalence of mutated MTHFR genotypes in spontaneously aborted embryos emphasises the potential protective role of periconceptional folic acid supplementation.

European Journal of Human Genetics (2002) 10, 113 -118. DOI: 10.1038/sj/ejhg/5200767

Keywords: methylenetetrahydrofolate reductase; MTHFR; polymorphism; folate; homocysteine; spontaneous abortion; foetal

Introduction

Methylenetetrahydrofolate reductase (MTHFR, EC 1.5.1.20) is a key enzyme in the folate dependent remethylation of

${ }^{*}$ Correspondence: H Zetterberg, Department of Clinical Chemistry and Transfusion Medicine, Sahlgrenska University Hospital, Göteborg University, S-413 45 Gothenburg, Sweden. Tel: +46 31 3423054; Fax: +46 31 828458; E-mail: henrik.zetterberg@clinchem.gu.se Received 14 September 2001; revised 29 November 2001; accepted 5 December 2001 homocysteine. The enzyme catalyses the conversion of 5,10methylenetetrahydrofolate into 5-methyltetrahydrofolate, the predominating circulating form of folate. 5-methyltetrahydrofolate participates in single-carbon transfers that occur as part of the synthesis of nucleotides, the remethylation of homocysteine to methionine, the synthesis of Sadenosylmethionine, and the methylation of DNA, proteins, neurotransmitters and phospholipids. ${ }^{1}$ MTHFR gene polymorphisms are commonly associated with hyperhomocysteinaemia ${ }^{2,3}$ which is a risk factor for neural tube defects 
(NTDs) ${ }^{4,5}$ and recurrent embryo loss. ${ }^{6-8}$ It is unclear how abnormalities of folate metabolism would cause compromised foetal viability, although both insufficient methylation of crucial metabolites and direct toxicity of homocysteine have been suggested as possible mediators of teratogenesis. ${ }^{9}$ Through their defects in folate dependent homocysteine metabolism, MTHFR polymorphisms have been implicated as risk factors for NTDs ${ }^{10-13}$ and recurrent embryo loss in early pregnancy. ${ }^{14,15}$

The best characterised MTHFR genetic polymorphism consists of a $677 \mathrm{C} \rightarrow \mathrm{T}$ transition $(\mathrm{C} 677 \mathrm{~T})$ which results in an alanine to valine substitution in the predicted catalytic domain of MTHFR. ${ }^{2}$ This substitution renders the enzyme thermolabile, and homozygotes and heterozygotes have about a $70 \%$ and 35\% reduced MTHFR activity in vitro, respectively. ${ }^{2}$ Homozygosity for the $677 \mathrm{~T}$ allele is associated with elevated homocysteine levels, predominantly in individuals who have a low plasma folate level. ${ }^{16}$ Furthermore, the level of plasma homocysteine can be lowered in homozygous individuals by folic acid supplementation. ${ }^{17}$ About half the general population carries at least one mutated allele and the frequency of the homozygous mutated genotype (677TT) ranges from 1 to $20 \%$ depending on the population. ${ }^{18}$

A second common polymorphism in the MTHFR gene is a $1298 \mathrm{~A} \rightarrow \mathrm{C}$ transition (A1298C) which results in a glutamate to alanine substitution within a presumed regulatory domain of MTHFR. ${ }^{3,19}$ The $1298 \mathrm{C}$ allele clearly leads to a decreased enzyme activity, although not to the same extent as the $677 \mathrm{~T}$ allele. ${ }^{3,19,20}$ Individuals who are homozygous for the $1298 \mathrm{C}$ allele have about a $40 \%$ reduced enzyme activity in vitro, but do not appear to have higher plasma homocysteine levels than controls. ${ }^{3,19}$ However, individuals who are compound heterozygous for the $677 \mathrm{~T}$ and $1298 \mathrm{C}$ alleles, which produces a $677 \mathrm{CT} / 1298 \mathrm{AC}$ genotype, have a $40-50 \%$ reduced MTHFR activity in vitro and a biochemical profile similar to that seen among 677T homozygotes with increased homocysteine levels and decreased folate levels. ${ }^{3,19}$ The A1298C polymorphism by itself may have clinically important effects on folate metabolism under conditions of low intake of folate or during times of high requirements of folate, like pregnancy and embryogenesis. ${ }^{3}$

In a recent examination of the common MTHFR polymorphisms in DNA samples from foetal tissue and neonatal cord blood, Isotalo et al. reported the existence of MTHFR 677CT/1298CC and 677TT/1298CC genotypes in the foetal but not in the neonatal group. ${ }^{21}$ They suggested that the $677 \mathrm{~T}$ and $1298 \mathrm{C}$ alleles can occur in cis and that three or four mutant alleles result in compromised foetal viability. The study group consisted of foetal tissue samples from both spontaneous and therapeutic terminations of pregnancy and it was not possible to read out if the different genotypes were detected in spontaneous or therapeutic abortions. The samples were analysed by PCR amplification and restriction fragment length polymorphism (RFLP). The use of MboII restriction digestion for detecting the A1298C polymorphism has been criticised because of interference with a silent polymorphism (T1317C) within the same exon. ${ }^{19}$ Moreover, it is not excluded that there may be other silent polymorphisms in the region making RFLP problematic. To further investigate the possible association between the common MTHFR C677T and A1298C polymorphisms and compromised foetal viability we analysed DNA samples from 80 spontaneously aborted human embryos for the MTHFR C677T and A1298C polymorphisms by using the solid-phase minisequencing technique. ${ }^{22}$ This technique directly detects all possible MTHFR C677T and A1298C genotype combinations and is not sensitive to silent polymorphisms.

\section{Materials and Methods}

\section{Clinical materials}

The study was approved by the Ethics Committee at the University Hospital of Heraklion and written informed consent was obtained from the relatives of all participants. The study group consisted of 80 foetal tissue samples from spontaneous abortions, obtained from the Department of Obstetrics and Gynecology, Medical School, University of Crete, Heraklion. Foetal death occurred between the sixth and twentieth week of pregnancy $(10.5 \pm 2.8)$, with the majority $(87.5 \%)$ occurring earlier than the twelfth week. The embryonic tissues were examined for maternal tissue contamination as previously described. ${ }^{23}$ Briefly, DNA paternity test was performed using a class of genetic markers at the four hyper-polymorphic short tandem repeat loci, HUMVWA31/1, HUMTHO1, HUMF13A1, and HUMFES/ FPS. ${ }^{24,25}$ The control group consisted of 125 DNA samples from healthy blood donors from Crete.

\section{DNA extraction and genotyping}

Genomic DNA was extracted as previously described. ${ }^{26}$ The study and control materials were analysed for the C677T and A1298C polymorphisms by the solid-phase minisequencing method. $^{22}$ Amplified genomic DNA from the MTHFR gene was obtained by multiplex PCR using the sense primer biotin5'-GGCTGACCTGAAGCACTTGAA-3' and the anti-sense primer 5'-GCATGCCTTCACAAAGCGGAA-3' for the C677T polymorphism and the sense primer 5'-CCCAAGGAGGAGCTGCTGAA-3' and the anti-sense primer biotin-5'GGTTCTCCCGAGAGGTAAAGAA-3' for the A1298C polymorphism. PCR reactions (50 $\mu$ t total volume) consisted of $2-$ 5 ng genomic DNA, 10 pmoles each of the C677T sense and anti-sense primers, 5 pmoles each of the A1298C sense and anti-sense primers, 1.0 unit of Taq polymerase (Roche, Mannheim, Germany) in $1 \times$ PCR-buffer (Roche, Mannheim, Germany) containing $1.5 \mathrm{mM} \mathrm{MgCl}_{2}$ and $0.2 \mathrm{mM}$ each of dGTP, dATP, dTTP and dCTP. $10 \mu$ l of the PCR products were added to 96-well streptavidine coated microtiter plates (Wallac, Turku, Finland) and incubated for $1.5 \mathrm{~h}$ at $37^{\circ} \mathrm{C}$. The bound DNA fragments were denatured with $50 \mu \mathrm{l}$ of $0.05 \mathrm{M} \mathrm{NaOH}$ for $5 \mathrm{~min}$ at room temperature. The microtiter 
plates were washed three times with a buffer containing $0.1 \%$ Tween, $50 \mathrm{~mm} \mathrm{NaCl}, 1 \mathrm{~mm}$ EDTA and $40 \mathrm{~mm}$ Tris-HCl, $\mathrm{pH}$ 8.8. $10 \mu \mathrm{l}$ of a solution containing 0.025 units of Thermo Sequenase DNA polymerase (Amersham Pharmacia Biotec, Uppsala, Sweden), 10 fmoles each of fluorescent ddATP and ddGTP, 200 fmoles of fluorescent ddCTP (NEN, Boston, MA, USA) and 4 pmoles of minisequencing primers was added. Minisequencing primers for the C677T and A1298C polymorphisms were 5'-GCGTGATGATGAAATCG-3' and 5T(10)GGAGCTGACCAGTGAAG-3', respectively. The poly(T) sequence of the latter was added to modify the electrophoretic mobility of the primer. The minisequencing reactions were allowed to proceed in the wells for $10 \mathrm{~min}$ at $58^{\circ} \mathrm{C}$. After the reaction, the plates were washed three times. The extended primers were released from the PCR products by adding $15 \mu \mathrm{l}$ formamide and incubation at $45^{\circ} \mathrm{C}$ for $5 \mathrm{~min}$, separated and analysed in the same reaction by capillary electrophoresis and laser-induced fluorescence in an ABI 310 genetic analyser (PE Applied Biosystems, Foster City, CA, USA).

\section{Statistical analysis}

MTHFR allele frequencies were determined for the study and control groups and compared by a Chi squared test. The prevalence of single and combined MTHFR genotypes was determined for both groups and compared by a two-tailed Fisher's exact test. Statistical significance was defined as $P<0.05$. Odds ratios and 95\% confidence intervals were calculated according to Altman. ${ }^{27}$ All analyses were performed using SYSTAT (SPSS Inc., Chicago, IL, USA).

\section{Results}

The MTHFR C677T and A1298C allele frequencies are presented in Table 1. In accordance with previous knowledge from other population studies mutated alleles were common in both groups. The $677 \mathrm{~T}$ allele frequency was 0.344 in the control group and 0.425 in the spontaneous abortion group. The 1298C allele frequency was 0.324 and 0.369 for the control and spontaneous abortion groups, respectively. The allele frequencies were not significantly different between the groups.

The individual genotype distributions for the control and spontaneous abortion groups are presented in Table 2 . There was a higher prevalence of the 1298AC genotype and a lower prevalence of the 1298AA genotype in the spontaneous abortion group compared with the control group $(P=0.003$ and $P=0.029$, respectively). The individual genotype distributions did not deviate significantly from Hardy-Weinberg equilibrium, except at the A1298C locus in the spontaneous abortion group, reflecting the overrepresentation of the 1298AC genotype in this group.

The combined C677T/A1298C genotype frequencies are presented in Table 3 . Only one of 80 spontaneously aborted embryos had the wild type combined MTHFR genotype (677CC/1298AA) as compared to the control group in which 19 of 125 individuals had 677CC/1298AA genotypes $(P=0.001)$. There was a higher prevalence of $677 \mathrm{CC} / 1298 \mathrm{AC}$ genotypes and a lower prevalence of 677CT/1298AA genotypes in the spontaneous abortion groups compared with the control group ( $P=0.023$ and $P=0.032$, respectively). Neither of the groups displayed triple (677CT/1298CC and 677TT/1298AC) or quadruple (677TT/1298CC) mutation combinations, suggesting complete linkage disequilibrium between the C677T and A1298C polymorphisms. The observed frequency of the combined 677TT/1298AA and $677 \mathrm{CT} / 1298 \mathrm{AC}$ genotypes, which both are associated with elevated plasma homocysteine concentrations, ${ }^{3,19}$ was significantly higher in the spontaneous abortion group compared with the control group $(P=0.015)$. We also grouped together subjects with at least one MTHFR mutated allele resulting in an odds ratio of 14.2 (95\% CI 1.78-113) when comparing spontaneously aborted embryos with controls $(P=0.001)$.

\section{Discussion}

The extent to which genetic variation contributes to the occurrence of spontaneous abortion remains unclear. The association between such occurrences and raised plasma homocysteine concentrations ${ }^{6-8}$ and the reports of increased risk of recurrent pregnancy loss among women with homozygosity for the MTHFR C677T polymorphism, ${ }^{14,15}$ were cues to the present investigation in which we determined the two common MTHFR gene polymorphisms (C677T and A1298C) in DNA samples from spontaneously aborted embryos and adult controls.

The MTHFR C677T allele frequencies and genotype distribution found in our control group agree well with those

Table 1 MTHFR allele frequencies for control and spontaneous abortion groups

\begin{tabular}{|c|c|c|c|c|}
\hline \multirow[b]{2}{*}{ MTHFR allele } & \multicolumn{2}{|c|}{ Observed frequency } & \multirow[b]{2}{*}{$\begin{array}{l}\text { Odds ratio } \\
(95 \% \mathrm{Cl})\end{array}$} & \multirow[b]{2}{*}{$p^{a}$} \\
\hline & $\begin{array}{l}\text { Control group } \\
(\mathrm{n}=125)\end{array}$ & $\begin{array}{l}\text { Spontaneous abortion } \\
\text { group }(\mathrm{n}=80)\end{array}$ & & \\
\hline $677 \mathrm{C}$ & 0.656 & 0.575 & $0.709(0.468-1.08)$ & 0.099 \\
\hline $1298 \mathrm{~A}$ & 0.676 & 0.631 & $0.820(0.537-1.25)$ & 0.351 \\
\hline $1298 \mathrm{C}$ & 0.324 & 0.369 & $1.22(0.798-1.86)$ & \\
\hline
\end{tabular}

${ }^{\mathrm{a} B y}$ Chi squared test. 
Table 2 Individual MTHFR genotype distributions for control and spontaneous abortion groups

\begin{tabular}{|c|c|c|c|c|}
\hline \multirow[b]{2}{*}{ MTHFR genotype } & \multicolumn{2}{|c|}{ Observed frequency } & \multirow[b]{2}{*}{$\begin{array}{l}\text { Odds ratio } \\
(95 \% \mathrm{Cl})\end{array}$} & \multirow[b]{2}{*}{$P^{a}$} \\
\hline & $\begin{array}{l}\text { Control group } \\
(\mathrm{n}=125)\end{array}$ & $\begin{array}{l}\text { Spontaneous abortion } \\
\text { group }(\mathrm{n}=80)\end{array}$ & & \\
\hline $677 C C$ & 0.416 & 0.350 & $0.756(0.418-1.37)$ & 0.380 \\
\hline $677 C T$ & 0.480 & 0.450 & $0.886(0.499-1.57)$ & 0.774 \\
\hline 677TT & 0.104 & 0.200 & $2.15(0.958-4.84)$ & 0.065 \\
\hline 1298AA & 0.456 & 0.300 & $0.511(0.279-0.937)$ & 0.029 \\
\hline $1298 \mathrm{AC}$ & 0.440 & 0.663 & $2.50(1.38-4.53)$ & 0.003 \\
\hline $1298 C C$ & 0.104 & 0.038 & $0.336(0.090-1.25)$ & 0.110 \\
\hline
\end{tabular}

${ }^{a}$ By Fisher's exact test.

Table 3 Combined C677T/A1298C genotype frequencies for control and spontaneous abortion groups

\begin{tabular}{|c|c|c|c|c|}
\hline \multirow[b]{2}{*}{ Genotype } & \multicolumn{2}{|c|}{ Observed frequency } & \multirow[b]{2}{*}{$\begin{array}{l}\text { Odds ratio } \\
(95 \% \mathrm{Cl})^{b}\end{array}$} & \multirow[b]{2}{*}{$p^{b, c}$} \\
\hline & $\begin{array}{l}\text { Control group } \\
(\mathrm{n}=125)^{a}\end{array}$ & $\begin{array}{l}\text { Spontaneous abortion } \\
\text { group }(\mathrm{n}=80)^{a}\end{array}$ & & \\
\hline \multicolumn{5}{|l|}{ MTHFR C677T/A1298C genotype: } \\
\hline CC/AA & 0.152 & 0.013 & $0.071(0.009-0.560)$ & 0.001 \\
\hline $\mathrm{CC} / \mathrm{AC}$ & 0.160 & 0.300 & $2.25(1.13-4.49)$ & 0.023 \\
\hline $\mathrm{CC} / \mathrm{CC}$ & 0.104 & 0.038 & $0.336(0.090-1.25)$ & 0.110 \\
\hline CT/AA & 0.200 & 0.088 & $0.384(0.155-0.951)$ & 0.032 \\
\hline CT/AC & 0.280 & 0.363 & $1.46(0.793-2.70)$ & 0.221 \\
\hline $\mathrm{CT} / \mathrm{CC}$ & NO & NO & ND & ND \\
\hline TT/AA & 0.104 & 0.200 & $2.15(0.958-4.84)$ & 0.065 \\
\hline TT/AC & NO & NO & ND & ND \\
\hline $\mathrm{TT} / \mathrm{CC}$ & NO & NO & ND & ND \\
\hline Combined TT/AA and CT/AC & 0.384 & 0.563 & $2.06(1.15-3.69)$ & 0.015 \\
\hline One or more MTHFR mutations & 0.848 & 0.988 & $14.2(1.78-113)$ & 0.001 \\
\hline
\end{tabular}

${ }^{\mathrm{a}} \mathrm{NO}=$ Not observed; ${ }^{\mathrm{b}} \mathrm{ND}=$ Not determined; ${ }^{\mathrm{C}}$ Fisher's exact test.

reported in a previous investigation of a Greek population. ${ }^{28}$ There is no previous investigation on the MTHFR A1298C polymorphism in Greeks. We observed a very high frequency of MTHFR 677T and 1298C alleles in the spontaneous abortion group. All but one of spontaneously aborted embryos carried at least one mutated allele. Although adult carriers of MTHFR polymorphisms only have a mildly disturbed folate metabolism due to decreased MTHFR activity, our data suggest that the effect of one or more MTHFR mutated alleles may be detrimental during embryogenesis when the folate requirement is high. ${ }^{29,30}$ The 677TT/1298AA and 677CT/1298AC genotypes that result in elevated homocysteine in adults ${ }^{3,19}$ also tended to be more frequent in the spontaneous abortion group when compared with controls but did not reach statistical significance. However, when combining the observed frequencies of the 677TT/1298AA and 677CT/1298AC genotypes there was a significant difference between the spontaneous abortion and control groups, suggesting that these genotypes are involved in the pathogenesis of spontaneous abortion.

There was a significantly higher prevalence of the individual 1298AC genotype and the combined 677CC/ 1298AC genotype in the spontaneous abortion group. The A1298C polymorphism affects enzyme regulation, possibly by $\mathrm{S}$-adenosylmethionine, an allosteric inhibitor of
MTHFR. ${ }^{31}$ It is not clear why the 1298AC genotype is overrepresented in the spontaneous abortion group while the 1298CC genotype tended to be less frequent in this group. Future studies with larger sample size will reveal whether the 1298AC genotype really affects foetal viability.

We observed a low frequency of 677CT/1298AA genotypes in the spontaneously aborted embryos. There is no obvious explanation for this statistical difference. There could be other favoured genotypes in addition to the wild type genotype. The 677CT/1298AA genotype may be underrepresented in the spontaneous abortion population because it may confer some selective advantage during embryogenesis. Single MTHFR 677 T or $1298 \mathrm{C}$ alleles may provide a regulatory balance between intracellular methylation reactions and the demand for DNA synthesis. This balance would be especially important during times of folate deficiency or high folate requirements. In accordance with this, Engbersen et al. have postulated that, in times of starvation, a reduced MTHFR activity will decrease homocysteine remethylation and so preserve the available one-carbon moieties of tetrahydrofolate metabolism for the vital synthesis of thymidine. ${ }^{32}$ However, our results demonstrate that a beneficial effect, if any, during embryogenesis would account only for the C677T polymorphism and not for the A1298C polymorphism. 
All homozygote subjects for either one of the MTHFR 677T and 1298C alleles had a wild type for the other polymorphism. We did not find any triple or quadruple mutation combinations (677CT/1298CC; 677TT/1298AC; 677TT/ $1298 \mathrm{CC})$, either in the study group or in the control group, suggesting complete linkage disequilibrium between the two polymorphisms with each of the mutations having evolved on a separate wild type allele. These data corroborate several earlier investigations in the field..$^{3,19,20,33}$ As the physical distance of $2.1 \mathrm{~kb}$ between the two polymorphisms is short, it is not surprising that recombination events very rarely have been observed. ${ }^{19,34,35}$ However, these and our results are in apparent contradiction with those reported in two studies by Isotalo et al. ${ }^{21,36}$ who found a substantial number of combined MTHFR 677TT/1298AC genotypes in adults (approximately 10\% of the study participants), ${ }^{36}$ neonates $(1.7 \%)^{21}$ and aborted embryos $(1.2 \%),{ }^{21}$ and $677 \mathrm{CT} / 1298 \mathrm{CC}$ and 677TT/1298CC genotypes selectively in aborted embryos $(3.7 \%) .{ }^{21}$ One reason for the conflicting results may be that the populations investigated by Isotalo et al. were of different descent compared with the ones studied by us and other groups. This is not a likely explanation since Weisberg et al. also studied a Canadian population and only found one individual with a MTHFR 677TT/1298AC genotype among 274 study participants ${ }^{19}$ compared with the high frequency reported by Isotalo et al. ${ }^{36}$ Both research groups used the original RFLP method by Frosst et al. for determining the C677T polymorphism. ${ }^{2}$ The MboII RFLP method used by Isotalo et al. for determining the A1298C polymorphism has been criticised because of interference with a silent polymorphism within the same exon with a prevalence of approximately $5 \%$ in the Canadian population. ${ }^{19}$ This would, however, only result in inaccurate identification of normal alleles. One problem with RFLP is that the method in general is sensitive to other sequence variations than that of interest. We have used the solid-phase minisequencing technique $^{22}$ for multiplex detection of the MTHFR C677T and A1298C polymorphisms. This technique detects all possible MTHFR C677T and A1298C genotype combinations simultaneously and is not sensitive to silent polymorphisms. Moreover, the simultaneous detection of both polymorphisms reduces the risk of sample mix-up.

Another notion concerning studies of the role of MTHFR polymorphisms on congenital defects and/or foetal viability is bias toward late-pregnancy outcomes. ${ }^{21}$ Since exposure to folic acid antagonists during the first or second months of pregnancy more than doubled the risk of NTDs ${ }^{37}$ and since the relative risk of having an infant with a congenital cardiovascular defect peaked by the maternal use of folic acid antagonists during the second and third months of pregnancy, $^{38}$ it is clear that foetal needs for folic acid are especially high early in embryogenesis. In addition, Martinelli et al. demonstrated that the C677T polymorphism does not add to the risk of unexplained late foetal loss (foetal death after 20 weeks or more of gestation). ${ }^{39}$ Thus we focused on spontaneously aborted foetuses earlier than twentieth week, $87.5 \%$ of them in the first trimester of pregnancy, so bias is unlikely to be present in this study.

The earlier findings, that the C677T polymorphism confers an even higher risk for NTDs if both the mother and her child are homozygous for the $677 \mathrm{~T}$ allele, as compared to if only the mother or the child was homozygous, ${ }^{12,40}$ suggest that such a maternal-foetal interaction may occur in the pathogenesis of spontaneous abortion as well. In our study maternal genotypes were not determined. Our results warrant additional investigations where both the maternal genotype and the genotype of the spontaneously aborted embryo are determined. Such an investigation could also help to resolve the conflicting results in the literature concerning the prevalence of triple and quadruple MTHFR mutations. However, the present finding of high prevalence of mutated MTHFR genotypes in spontaneously aborted embryos further emphasises the clinical and biological significance of this gene in foetal development, as well as the potential protective role of periconceptional folic acid supplementation.

\section{Acknowledgements}

This work was supported by grants from the Swedish Medical Research Council (project \#12103) and the Sahlgrenska University Hospital.

\section{References}

1 Rosenblatt DS. Inherited disorders of folate transport and metabolism; in Scriver CR, Beaudet AL, Sly WS, Valle D (eds): The metabolic and molecular bases of inherited disease. New York: McGraw Hill, 1995, pp 3111-3128.

2 Frosst P, Blom HJ, Milos R et al: A candidate genetic risk factor for vascular disease: a common mutation in methylenetetrahydrofolate reductase. Nat Genet 1995; 10: 111-113.

3 van der Put NMJ, Gabreëls F, Stevens EMB et al: A second common mutation in the methylenetetrahydrofolate reductase gene: an additional risk factor for neural-tube defects? Am J Hum Genet 1998; 62: $1044-1051$.

4 Steegers-Theunissen RPM, Boers GHJ, Trijbels FJM, Eskes TKAB: Neural-tube defects and derangement of homocysteine metabolism. N Engl J Med 1991; 324: 199-200.

5 Mills JL, McPartlin JM, Kirke PN et al: Homocysteine metabolism in pregnancies complicated by neural-tube defects. Lancet 1995; 345: $149-151$.

6 Steegers-Theunissen RPM, Boers GHJ, Blom HJ, Trijbels FJM, Eskes TKAB: Hyperhomocysteinaemia and recurrent spontaneous abortion or abruptio placentae. Lancet 1992; 339: 11221123

7 Wouters MGAJ, Boers GHJ, Blom HJ et al: Hyperhomocysteinemia: a risk factor in women with unexplained recurrent early pregnancy loss. Fertil Steril 1993; 60: 820-825.

8 Nelen WLDM, Blom HJ, Steegers EAP, den Heijer M, Eskes TKAB: Hyperhomocysteinemia and recurrent early pregnancy loss: a meta-analysis. Fertil Steril 2000; 74: 1196-1199.

9 Rosenquist TH, Ratashak SA, Selhub J: Homocysteine induces congenital defects of the heart and neural tube: effect of folic acid. Proc Natl Acad Sci 1996; 93: 15227-15232.

10 van der Put NMJ, Steegers-Theunissen RPM, Frosst P et al: Mutated methylenetetrahydrofolate reductase as a risk factor for spina bifida. Lancet 1995; 346: 1070-1071. 
26 Field JK, Kiaris H, Howard P, Vaughan ED, Spandidos DA, Jones AS: Microsatellite instability in squamous cell carcinoma of the head and neck. Br J Cancer 1995; 71: 1065 - 1069

27 Altman DG. Practical statistics for medical research. London, Chapman \& Hall/CRC, 1991, pp. 268-269.

28 Antoniadi T, Hatzis T, Kroupis C, Economou-Petersen E, Petersen MB: Prevalence of factor V Leiden, prothrombin G20210A, and MTHFR C677T mutations in a Greek population of blood donors. Am J Hemat 1999; 61: 265-267.

29 McPartlin J, Halligan A, Scott JM, Darling M, Weir DG: Accelerated folate breakdown in pregnancy. Lancet 1993; 341: $148-149$.

30 Higgins JR, Quinlivan EP, McPartlin J, Scott JM, Weir DG, Darling MR: The relationship between increased folate catabolism and the increased requirement for folate in pregnancy. BJOG 2000; 107: $1149-1154$.

31 Rozen R: Molecular genetics of methylenetetrahydrofolate reductase deficiency. J Inherit Metab Dis 1996; 19: 589-594.

32 Engbersen AMT, Franken DG, Boers GHJ, Stevens EMB, Trijbels FJM, Blom HJ: Thermolabile 5,10-methylenetetrahydrofolate reductase as a cause of mild hyperhomocysteinemia. Am J Hum Genet 1995; 56: 142-150.

33 Stegmann K, Ziegler A, Ngo ETKM, Kohlschmidt N, Schröter B, Ermert A, Koch MC: Linkage disequilibrium of MTHFR genotypes $677 \mathrm{C} / \mathrm{T}-1298 \mathrm{~A} / \mathrm{C}$ in the German population and association studies in probands with neural tube defects(NTD). Am J Med Genet 1999; 87: 23-29.

34 Friedman G, Goldschmidt N, Friedlander Y et al: A common mutation $\mathrm{A} 1298 \mathrm{C}$ in human methylenetetrahydrofolate reductase gene: association with plasma total homocysteine and folate concentrations. J Nutr 1999; 129: 1656-1661.

35 Hanson NQ, Aras O, Yang F, Tsai MY: C677T and A1298C polymorphisms of the methylenetetrahydrofolate reductase gene: incidence and effect of combined genotypes on plasma fasting and post-methionine load homocysteine in vascular disease. Clin Chem 2001; 47: 661-666.

36 Isotalo PA, Donnelly JG: Prevalence of methylenetetrahydrofolate reductase mutations in patients with venous thrombosis. Mol Diagn 2000; 5: 59-66.

37 Hernández-Díaz S, Werler MM, Walker AM, Mitchell AA: Neural tube defects in relation to use of folic acid antagonists during pregnancy. Am J Epidemiol 2001; 153: 961 - 968.

38 Hernández-Díaz S, Werler MM, Walker AM, Mitchell AA: Folic acid antagonists during pregnancy and the risk of birth defects. N Engl J Med 2000; 343: 1608-1614.

39 Martinelli I, Taioli E, Cetin I et al: Mutations in coagulation factors in women with unexplained late fetal loss. $N$ Engl J Med 2000; 343: 1015 - 1018 .

40 van der Put NMJ, Trijbels FJM, Hol F et al: Mutated methylenetetrahydrofolate reductase in sporadic and hereditary spina bifida offspring; in Mato JM, Caballero A (eds): Proceedings of III workshop on methionine metabolism, molecular mechanism and clinical implications. Consejo Superior de Investigaciones Cientificas, Madrid, 1996, pp 186-191. 